\title{
Centro de material e esterilização: estudo do tempo efetivo de trabalho para dimensionamento de pessoal
}

\author{
Effective working time of nursing staff dimensioning at the sterilization center
}

Centro de Esterilización: estudio del tiempo de trabajo efectivo del personal de enfermería

Márcia Elisa Binder Neis ${ }^{\mathrm{I}}$, Francine Lima Gelbcke ${ }^{\mathrm{II}}$, Nádia Chiodelli Salum ${ }^{\mathrm{III}}$, Tânia Teotônia de Oliveira ${ }^{\mathrm{IV}}$

\section{RESUMO}

$\mathrm{O}$ adequado dimensionamento de pessoal de enfermagem tem sido motivo de inquietação para enfermeiros gestores, principalmente em áreas específicas como Centro de Material e Esterilização. Este estudo teve por objetivo mensurar o tempo efetivo de trabalho do pessoal de enfermagem do Centro de Material e Esterilização. Os dados foram coletados no Centro de Material e Esterilização de um Hospital Universitário, em 2006, utilizando a observação direta das atividades realizadas pelos trabalhadores de enfermagem e registro dos dados em instrumento, sendo analisados por estatística descritiva. Os resultados apontaram que o tempo efetivo de trabalho foi de $81,20 \%$, considerado excelente, confirmando o preconizado pela literatura, que aponta $85,0 \%$. Conclui-se que o tempo efetivo de trabalho do pessoal de enfermagem do Centro de Material e Esterilização equivale-se ao descrito nos estudos para as unidades com a presença do paciente.

Descritores: Recursos Humanos; Gerenciamento do tempo; Enfermagem; Esterilização.

\section{ABSTRACT}

The appropriate dimensioning of nursing staff has been concerned nurses managers, especially as in specific areas like the Sterilization Centre (SC). This study aims to measure the effective working time of nursing staff at the SC. The data were collected in the SC of a university hospital in 2006, using as a methodological strategy, the direct observation of nursing staff and recording the data in an instrument of control, which were analyzed by descriptive statistics. The results indicate that the working time was $81,20 \%$, classified as excellent, supported by literature that describes the value of $85 \%$. It was concluded that the effective working time for nursing staff in the SC is similar to that described in other studies considering hospital units having in patients.

Descriptor: Human Resources; Time Management; Nursing; Sterilization.

\section{RESUMEN}

El dimensionamiento de la equipa de enfermería ha sido motivo de preocupación para las enfermeras gestoras, sobre todo en áreas específicas como la central de esterilización (CE). El estudio tuvo como objetivo medir el tiempo efectivo de trabajo de los trabajadores de enfermería del CME Los datos fueron recogidos en la CME de un hospital universitario en 2006, utilizándose como estrategia metodológica la observación directa del personal de enfermería y los datos fueran registrados en uno instrumento de controle y analizado por estadística descriptiva. Los resultados indicaron que el tiempo de trabajo efectivo fue $81,20 \%$, que es excelente, en concordancia a las recomendaciones en la literatura que es de $85 \%$. Así, el trabajo efectivo de las equipes de enfermería en una SC es similar con los descriptos en otros estudios considerando las unidades hospitalarias con pacientes internados.

Descriptores: Recursos Humanos; Administración del Tiempo; Enfermería; Esterilización.

\footnotetext{
I Enfermeira, Especialista em Enfermagem em Saúde do Adulto e Administração Hospitalar, Discente do Programa de Pós-Graduação em Enfermagem (PEN), nível Mestrado Profissional, da Universidade Federal de Santa Catarina (UFSC). Enfermeira chefe do Centro de Esterilização do Hospital Universitário (HU), UFSC. Florianópolis, SC, Brasil. E-mail: marcianeis@gmail.com.

II Enfermeira, Doutora em Enfermagem. Professor Adjunto, Departamento de Enfermagem, UFSC. Florianópolis, SC, Brasil. E-mail: fgelbcke@ccs.ufsc.br.

III Enfermeira, Doutora em Enfermagem. Professor Adjunto, Departamento de Enfermagem, UFSC. Florianópolis, SC, Brasil. E-mail: nchiodelli@gmail.com.

IV Enfermeira, Especialista em Enfermagem em Saúde do Adulto e Administração Hospitalar. Enfermeira chefe do Centro de Esterilização do HU, UFSC. Florianópolis, SC, Brasil. E-mail: tannytn@gmail.com.
} 


\section{INTRODUÇÃO}

Uma das dificuldades do enfermeiro gestor é justificar a reposição ou expansão do quadro do pessoal de enfermagem na administração das instituições de saúde, o que pode estar ocorrendo por influência das limitações para sistematizar e apoiar as propostas nas atuais fórmulas matemáticas, que se mostram inconsistentes frente aos custos da instituição ${ }^{(1-3)}$.

Este problema amplia-se quando o setor é o Centro de Material e Esterilização (CME), definida como uma "Unidade funcional localizada nos serviços de saúde destinada ao processamento de produtos para saúde"(4).

O CME apresenta algumas especificidades como a organização dos processos de trabalho em áreas fracionadas, extensa complexidade de tarefas, ausência do paciente e a falta de reconhecimento profissional contribuindo para desestimular investimentos nesta área ${ }^{(1)}$.

Outro fator que merece destaque é que o cuidado indireto é menos valorizado que o cuidado direto ao cliente, mesmo com o discurso de que este instrumentaliza a prestação do cuidado direto, sendo este um dos aspectos encontrados no $\mathrm{CME}^{(5-7)}$. A própria academia dá pouca ênfase à área de Centro de Material e Esterilização, reforçando a invisibilidade deste $\operatorname{setor}^{(1,8)}$.

Diante destes aspectos, os administradores das instituições de saúde, frente à necessidade de oferecer assistência imediata e segura aos pacientes, procuram equacionar os recursos humanos disponíveis, sendo obrigados, muitas vezes, a privilegiarem as unidades assistenciais em detrimento daquelas não envolvidas no cuidado direto ao paciente ${ }^{(3)}$.

Para subsidiar os enfermeiros, o Conselho Federal de Enfermagem (COFEN), por meio da Resolução 293/04, faz considerações quanto ao dimensionamento de pessoal de enfermagem, no entanto, caracteriza o CME como uma sala de esterilização e propõe o cálculo através de sítios funcionais ${ }^{(9)}$, o que na prática não se mostrou facilmente aplicável. Esta proposta parte de uma premissa de alocar os funcionários por área técnica, conforme as atividades exigem (sítio funcional), mas não mensura a produção diária de pacotes processados.

Entre os estudos consultados, destacam-se os de Gaidzinski ${ }^{(10-11)}$ os quais tratam do desenvolvimento de uma equação matemática para o cálculo de pessoal de enfermagem incluindo nesta estimativa a complexidade assistencial $^{(10)}$. A aplicação desta equação é recomendada para identificação das seguintes variáveis: carga de trabalho da unidade; índice de segurança técnica (IST) e tempo efetivo de trabalho(10).

Quanto ao tempo efetivo de trabalho, pesquisadores consideram que entre 75 e $85 \%$ do tempo total trabalhado é considerado excelente $e^{(5,12)}$.

Para tanto, adota-se o pressuposto de que o tempo efetivo de trabalho no CME é o tempo que o trabalhador dedica às atividades desenvolvidas no setor durante seu turno de trabalho, tais como: limpeza, secagem, inspeção, empacotamento, identificação, esterilização, guarda e distribuição de material esterilizado, subtraindo-se o tempo que ele realiza outras ações que não são pertinentes ao serviço, como lanches, telefonemas, necessidades fisiológicas, conversas paralelas, serviço de banco, consultas médicas, entre outros $^{(10)}$.

Diante das diferenças entre os setores que prestam assistência ao paciente, considera-se que os tempos de assistência de enfermagem referendados na literatura podem ser testados e validados na realidade de cada serviço ${ }^{(11)}$.

Evidencia-se que a maioria dos métodos de dimensionamento de pessoal de enfermagem considera como tempo efetivo de trabalho o tempo diário de trabalho determinado pelas instituições de saúde ${ }^{(11)}$, no entanto pondera-se que os trabalhadores não produzem igualmente durante todo o período de trabalho, pois realizam atividades pessoais que são extras às suas tarefas profissionais ${ }^{(10)}$.

Neste sentido, devem ser consideradas as perdas de produtividade dos trabalhadores de enfermagem mediante a redução das horas disponíveis do trabalhador em seus turnos de trabalho, quando nas horas médias adotadas para o dimensionamento de pessoal de enfermagem, essa variável não estiver incluída.

É importante para a realidade brasileira, confirmar os pressupostos levantados de que o número de horas de enfermagem está diretamente relacionado com a segurança dos pacientes e que melhores níveis no quadro de enfermagem resultam num decréscimo da média de permanência no hospital, diminuição das taxas infecção urinária, pneumonia e choque ${ }^{(13)}$.

Dessa forma, este estudo teve como objetivo mensurar o tempo efetivo de trabalho do pessoal de enfermagem do Centro de Material e Esterilização como uma das variáveis do dimensionamento de pessoal de enfermagem, com base no proposto por Gaidzinski ${ }^{(10)}$, haja vista que as peculiaridades do CME podem divergir daquelas mensuradas em outras unidades hospitalares. 


\section{METODOLOGIA}

Pesquisa descritiva de abordagem quantitativa realizada no CME de um hospital universitário no período de junho a julho de 2006. A instituição atua nos três níveis de assistência, sendo referência estadual em patologias complexas, clínicas e cirúrgicas, com elevada demanda na área de câncer e cirurgias de grande porte, assistindo em nível de emergência, UTI, hemodiálise, ambulatório, maternidade e unidades de internação.

O CME estudado conta em seu quadro de pessoal com 28 trabalhadores, dos quais duas enfermeiras, 14 auxiliares de saúde (atendentes de enfermagem), 10 auxiliares de enfermagem e dois técnicos de enfermagem, distribuídos em turnos de seis horas (manhã e tarde) e turnos de 12 horas (finais de semana, feriados e noturno).

Fizeram parte da amostra os trabalhadores que se dispuseram a participar do estudo e que atuam no período diurno, num total de 21 pessoas. Os mesmos foram orientados e convidados a tomar parte do estudo, garantindo sua liberdade de participação e desistência em qualquer momento, sem prejuízo profissional. 0 aceite se deu por meio da assinatura do termo de consentimento livre e esclarecido (TCLE), com anonimato garantido pela utilização de letras para identificação dos registros. O projeto foi submetido ao Comitê de Ética em Pesquisa da Universidade Federal de Santa Catarina e aprovado sob o registro 008/06.

A coleta de dados foi realizada pela pesquisadora auxiliada por uma bolsista orientada pela mesma, e ocorreu utilizando-se a observação direta dos trabalhadores durante suas atividades diárias nas diversas áreas que compõe o CME. Para o registro dos dados relacionados ao tempo efetivo de trabalho foi construído um instrumento que consta de duas partes: a primeira visou à caracterização dos trabalhadores quanto ao: sexo, idade, turno, tempo de trabalho no $C M E$, registro da hora de chegada e saída no setor, atividades para as quais o trabalhador estava designado, o tempo de início e término das atividades. Na segunda parte foram registradas as atividades realizadas, incluindo as inerentes ao trabalho e as atividades extras realizadas no turno de trabalho como: refeições, necessidades fisiológicas, telefonemas e conversas particulares, saídas para o banco, consultas médicas, visita a parentes internados, trocas de plantões na escala entre outros.

Para mensurar a variável tempo efetivo de trabalho, foi considerada a jornada de trabalho diária de cada trabalhador como $100 \%$. A partir desta, foram levantadas as atividades executadas no processo de trabalho, descontando-se o tempo despendido com outras atividades não relacionadas ao trabalho (registradas na segunda parte do instrumento). Para o processo de observação, foi definido que cada trabalhador seria acompanhado durante todo o seu turno de trabalho (360 minutos), subtraindo o número de minutos registrados na segunda parte do instrumento de coleta de dados correspondente aos afastamentos (" $X$ " minutos). Os dados foram calculados por meio do programa Excel. A jornada de trabalho subtraindo-se o tempo despedido com outras atividades caracterizou o tempo efetivamente trabalhado.

A fim de constituir um parâmetro mais fidedigno, cada um dos 21 trabalhadores foi observado no mínimo em três e no máximo em quatro turnos de trabalho, totalizando 86 observações. Para análise dos dados foi utilizada estatística descritiva, com somatória dos tempos em atividades de trabalho e extras, estabelecendo-se o percentual de tempo trabalhado e em atividades extras, visando definir a média de tempo efetivamente trabalhado.

\section{RESULTADOS E DISCUSSÃO}

Os dados apresentados referem-se à caracterização da força de trabalho e o tempo efetivo de trabalho.

Quanto à caracterização da força de trabalho, entre os trabalhadores que constituíram a amostra do estudo, identificou-se que a maioria possui entre 40 e 45 anos, com atuação em torno de 10 anos no $\mathrm{CME}_{\text {, sendo } 80 \%}$ do sexo feminino. Na enfermagem, os estudos retratam que a maior parcela da força de trabalho em saúde é do sexo feminino e há estudos que afirmam que no CME estão lotados trabalhadores com uma idade mais avançada, muitos já próximos da aposentadoria(14-16).

Nas instituições de saúde, é no CME que se realiza o processamento dos produtos para a saúde, envolvendo as seguintes atividades: recepção, limpeza, secagem, inspeção da limpeza, avaliação da funcionalidade, preparo (controle, organização e acondicionamento), esterilização, monitorizarão das etapas, armazenamento e distribuição dos produtos para saúde ${ }^{(4)}$.

É, portanto, um local com uma dinâmica de funcionamento que requer cumprimento de normas técnicas para o desenvolvimento das atividades, necessitando de protocolos minuciosos para garantia da eficácia dos resultados ${ }^{(14)}$, exigindo atenção e atualização constante dos trabalhadores que lá atuam. 
O CME é centralizado, ou seja, realiza todo o preparo e esterilização dos produtos para a saúde com área física exclusiva que abriga as áreas técnicas do expurgo, preparo, esterilização, armazenamento (arsenal) e distribuição de material esterilizado. Nesse sentido, o processo de trabalho do CME é distribuído entre os trabalhadores de enfermagem nestas diversas áreas.

Considerando a dinâmica de trabalho no $\mathrm{CME}$, para analisar o tempo efetivo de trabalho, foram avaliadas as diversas atividades realizadas pelo pessoal de enfermagem que atua nesta unidade, sendo que os dados que compuseram a segunda parte do instrumento possibilitaram analisar o tempo efetivo de trabalho, aspecto central deste estudo.

No Gráfico 1 apresenta-se a o percentual de horas trabalhadas em cada turno de trabalho pelo pessoal de enfermagem do CME.

Gráfico 1: Distribuição do tempo médio trabalhado por turno pelo pessoal de enfermagem do CME de um hospital universitário. Florianópolis, SC, 2006.

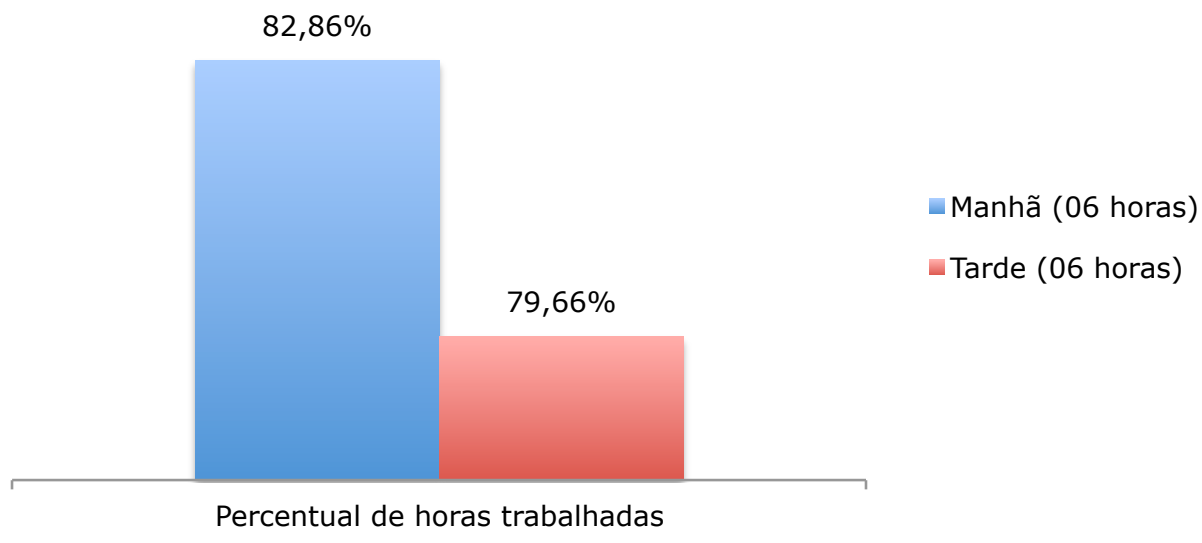

Considerando-se os resultados do Gráfico 1, observa-se que o tempo efetivo trabalhado nos turnos manhã e tarde foram muito contíguos, sendo que o turno da manhã $(82,86 \%)$ apresenta um percentual de horas efetivamente trabalhados modestamente superior ao turno da tarde $(79,66 \%)$. Para chegar-se a este resultado, somaram-se as horas trabalhadas de cada período, manhã ou tarde, e dividiu-se pelo número de dias observados naquele período, fazendo-se uma média por turno de trabalho.

Cabe ressaltar que os processos de trabalho entre os turnos são diferentes em alguns pontos, como por exemplo, o turno matutino concentra mais as atividades de reposição de roupas e do estoque de material esterilizado, enquanto no turno da tarde destaca-se o processamento das caixas cirúrgicas. Esta distribuição das atividades pode interferir nas horas trabalhadas, haja vista que no processamento das caixas há necessidade de maior concentração, exigindo checagem de peças pequenas, além de ser um trabalho também mais pesado fisicamente, considerando-se o peso das caixas, o que pode estar influenciando nas atividades extras realizadas pelos trabalhadores, que necessitam de um espaço para relaxar, de um respiradouro.
Sob outra ótica, conforme Tabela 1, observou-se que o número de cirurgias diárias no Centro Cirúrgico parece não estar interferindo no percentual de horas efetivas trabalhadas, mesmo que este setor apresente elevada demanda de atividades para o CME. 
Tabela 1: Relação entre o número diário de cirurgias no Centro Cirúrgico e o percentual médio de horas trabalhadas pelo pessoal de enfermagem do CME de um hospital universitário. Florianópolis, SC, 2006.

\begin{tabular}{|c|c|}
\hline No de Cirurgias & Horas trabalhadas (\%) \\
\hline 14 & 91,12 \\
\hline 11 & 85,27 \\
\hline 05 & 84,99 \\
\hline 13 & 84,25 \\
\hline 11 & 83,61 \\
\hline 10 & 82,74 \\
\hline 16 & 82,70 \\
\hline 02 & 80,16 \\
\hline 10 & 79,36 \\
\hline 18 & 78,90 \\
\hline 03 & 75,90 \\
\hline 12 & 75,55 \\
\hline 10 & 74,53 \\
\hline
\end{tabular}

Analisando a Tabela 1, identificou-se que a demanda de atividades provenientes do Centro Cirúrgico (CC), não mostrou interferir no tempo efetivo de trabalho. Essa relação se observa, por exemplo, no dia em que ocorreram apenas duas cirurgias e o número de horas efetivamente trabalhadas foi de $80,16 \%$ e o dia com maior número de cirurgias, 18 , foi de $78,90 \% \%$, ou seja, percentuais próximos. O máximo de horas trabalhadas foi de $91,12 \%$, quando o CC realizava 14 cirurgias e o mínimo foi de 74,53\%, com 10 cirurgias.

Perante este quadro, correlacionamos que as horas efetivas trabalhadas tenham mais relação com a responsabilidade com que o funcionário assume suas atividades do que com o quantitativo de atividades a serem realizadas. Um dos problemas evidenciados na força de trabalho do $C M E$, é que os trabalhadores de enfermagem ali locados, raramente optaram por trabalhar nesta área ${ }^{(8)}$, seja pelo desprestígio ligado à execução das tarefas, ou apresentaram problemas de relacionamento em outras áreas, ou de saúde, ou próximo à aposentadoria ${ }^{(8,15,17)}$. Como já apontado anteriormente, em muitas situações os administradores hospitalares visando garantir a assistência imediata e segura aos pacientes, procuram equacionar os recursos humanos disponíveis, distribuindo o pessoal de enfermagem nas unidades assistenciais, em detrimento daquelas não envolvidas no cuidado direto ao paciente ${ }^{(3)}$.

No entanto, é importante ressaltar que o CME para funcionar adequadamente necessita de pessoal qualificado e a quantidade desta força de trabalho depende dos recursos materiais existentes, de estrutura física, da utilização de técnicas padronizadas e da racionalização do trabalho(15). Interfere também no dimensionamento, o tipo de instituição no qual está inserido, com emergência e/ou maternidade, número de salas cirúrgicas.

Outro aspecto analisado relacionou-se ao tempo efetivo de trabalho e a área técnica de trabalho no $\mathrm{CME}$ para o qual o funcionário estava designado. De um modo geral, as áreas descritas acima englobam atividades como: Expurgo (recebimento, descontaminação e limpeza do material contaminado); Preparo 1 (secagem e inspeção dos materiais com verificação da funcionalidade e integridade dos mesmos, conferência e montagem dos pacotes para esterilizar); Preparo 2 (recebimento material das unidades da instituição na janela do expurgo, guarda e montagem dos pacotes de campos cirúrgicos, conferência dos impressos de débitos, montagem dos carrinhos com os kits de cada cirurgia); Preparo 3 (conferência e montagem caixas e pacotes a serem processados, verificação validade dos materiais esterilizados, conferência materiais consignados e material termossensível que serão encaminhados para empresa terceirizada); Autoclave (montagem e desmontagem da carga da Autoclave, registro da carga/ciclo/lote para rastreabilidade, realização monitorização química, física e biológica dos processos de esterilização, guarda do material esterilizado no arsenal), entre outras.

Como colocado anteriormente, cada uma das áreas possui processos de trabalho diferenciados, o que nos fez inferir que haveria uma diferença do tempo efetivo de trabalho por área. No Gráfico 2 são apresentados os dados relativos a esta relação. 
Gráfico 2: Distribuição do tempo médio efetivo de trabalho nas áreas técnicas do CME pelos trabalhadores de enfermagem de um hospital universitário. Florianópolis, SC, 2006.

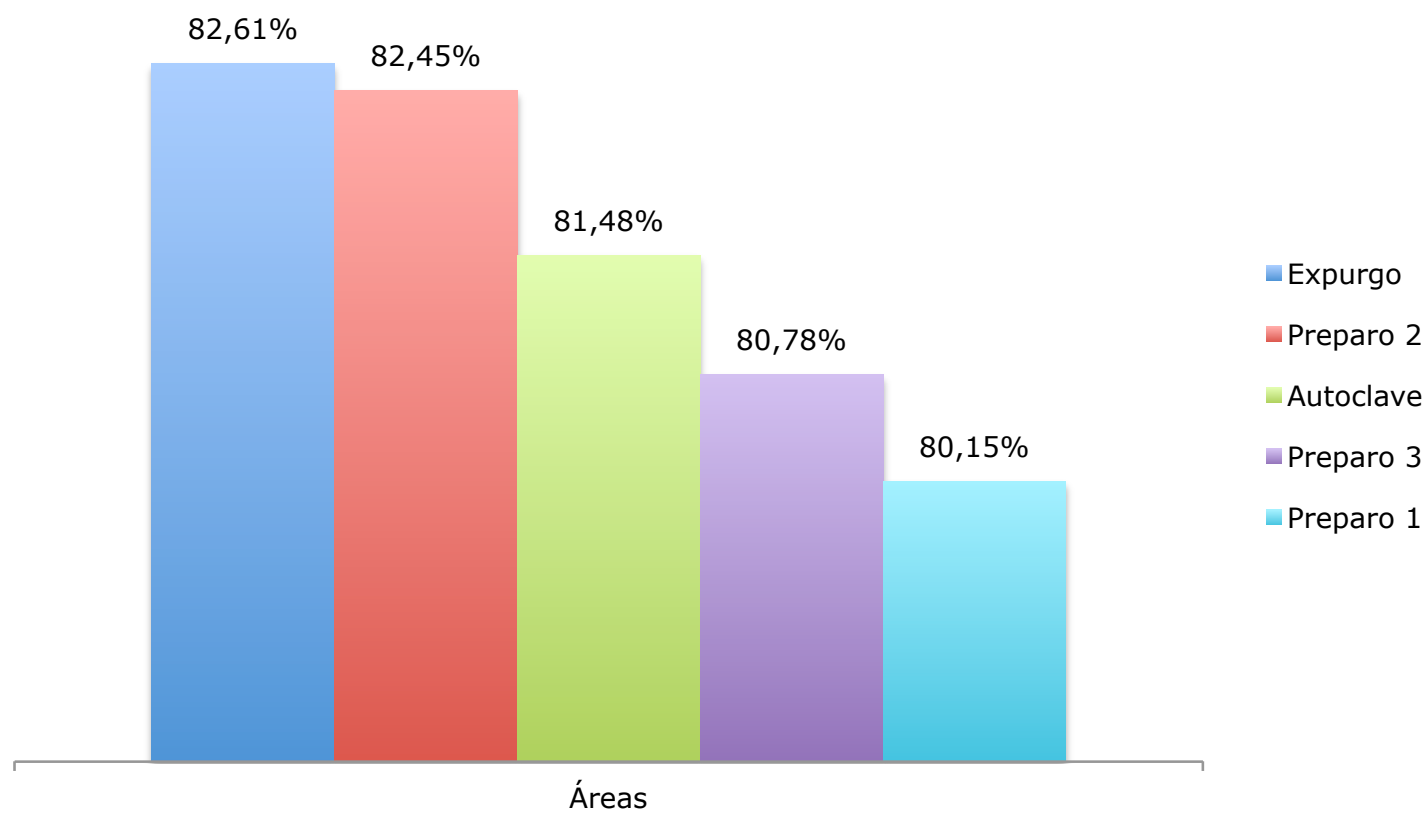

Analisando os dados apresentados no Gráfico 2, evidenciamos que no expurgo o número de horas trabalhadas correspondeu a $82,61 \%$, sendo o lugar onde o tempo efetivo trabalhado foi maior. As causas podem estar relacionadas ao fato de que o início do processamento se dá nesta área, onde todo o material tem sua entrada, com um volume significativo de trabalho, além do fato de utilizarem uma paramentação específica, com a qual não podem circular em outras áreas.

Neste contexto, a segunda área onde o tempo efetivo foi maior $(82,45 \%)$ foi o preparo 2 , área que também se caracteriza como entrada e saída dos produtos para saúde no setor. O trabalhador que está destinado a esta área recebe os materiais contaminados e fornece os materiais esterilizados.

A partir da Autoclave $(81,48 \%)$, Preparo $3(80,78 \%)$ e Preparo $1(80,15 \%)$ houve um decréscimo progressivo no tempo efetivo de trabalho, pois as atividades vão se diluindo nas diversas áreas do CME.

Como os processos de trabalho são distintos em cada área técnica, mensuraram-se as diferenças de atividades por área, no sentido de avaliar se também se traduziriam no tempo efetivo de trabalho. O expurgo caracteriza-se como área de alta contaminação, que manuseia matéria orgânica, necessita paramentação específica, maquinário e insumos adequados. A área de preparo apresenta tarefas sequenciais e minuciosas, como montagem de caixas, bandejas e pacotes, dobras de campos cirúrgicos específicos, enfim não esgota suas atividades nunca. A área das autoclaves se caracteriza por ser de risco (quanto a queimaduras), esforço físico (pelo manuseio de caixas pesadas, abertura das portas da Autoclave) e requer conhecimento e habilidade para manejo dos equipamentos e controle das monitorizações, inferindo tempo elevado de trabalho e alta concentração.

Neste contexto, apesar das diferenças de atividades das áreas, todas implicam em responsabilidade, conhecimento e apresentam interdependência de ações de um processo de trabalho integral que se subdivide em processos menores por área de atividade (expurgo, preparo, autoclave), as quais têm o objetivo comum de fornecer material esterilizado às unidades consumidoras com todas as garantias que envolvem o reprocessamento.

É primordial ressaltar que a CME compreende um importante setor de apoio à instituição de saúde, relacionando no combate às infecções, na segurança dos produtos que fornece resultando na qualidade dos serviços prestados ${ }^{(8,16)}$.

Correlacionando-se os resultados por área técnica, observou-se que os mesmos foram muito próximos e que os diferentes processos de trabalho não mostraram interferir no tempo efetivo de trabalho pelos trabalhadores de enfermagem. 
Outro aspecto verificado foi onde e o que o pessoal de enfermagem estava fazendo quando não se encontrava trabalhando, apesar de estarem no seu turno de trabalho.

Conforme os dados levantados, o item outras atividades somou 97 horas, resultado das observações dos 21 trabalhadores. A sala de lanche foi o local onde o funcionário mais emprega seu tempo não trabalhado, pois as pessoas a frequentam não só para lanchar, mas também para conversar, tomar água, chá, remédios e afins. Em estudo realizado em dois CME públicos, foi identificado que o local do lanche, das refeições, é também um local de encontro, de confraternização, o que pode caracterizar-se como um espaço de socialização, mas também como uma forma de suportar o próprio processo de trabalho, como uma válvula de escape $^{(14)}$.

O item "outros" inclui recebimento de colegas e/ou parentes no setor de trabalho, aquisição e pagamento de objetos pessoais, marcação de consultas, exames, sendo este o segundo item mais levantado como desvio das atividades efetivas de trabalho pelo funcionário.

Outro aspecto observado foi que os trabalhadores permanecem grande parte do turno num mesmo ambiente, como as mesas de preparo e empacotamento. Esta forma de organizar o trabalho pode favorecer a conversa e a dispersão, porém também se constitui em momentos de discussão do próprio processo de trabalho, o que favorece as relações estabelecidas na equipe.

Estas conversas, no entanto, se por um lado influenciam no tempo efetivo de trabalho, por outro possibilitam as trocas, as interações, o que permite um ambiente de trabalho agradável. Pode-se dizer que em torno da mesa, com as conversas, estabelecem uma válvula de escape frente a um trabalho rotineiro, que pouco possibilita a criatividade do trabalhador ${ }^{(14,17)}$. No entanto, estudo aponta que as atividades realizadas em torno da mesa permitem conversas, aproximação entre os trabalhadores, mas também podem gerar conflitos e estes sim podem interferir no tempo efetivo de trabalho ${ }^{(14)}$.

As saídas do CME incluíram idas ao banco, ao supermercado e farmácia, bem como almoço e similares. O uso do telefone para questões pessoais revelou um quantitativo pequeno em relação aos outros aspectos, talvez pela necessidade frequente de utilização do mesmo para questões de trabalho, e a orientação dos enfermeiros aos trabalhadores da importância de mantêlo livre para uso em serviço.
No total, os trabalhadores foram observados em 86 turnos de seis horas, perfazendo 516 horas trabalhadas $(100 \%)$, e o percentual de horas efetivamente trabalhadas foi de $81,20 \%$ (419 horas trabalhadas). Ou seja, das 516 horas, 97 horas foram consideradas horas de realização de atividades extra serviço. Este índice de produtividade dos trabalhadores deste CME está dentro do nível excelente, já que índices acima de $80 \%$ são considerados excelentes ${ }^{(10)}$.

É importante salientar que houve diferença nos dados colhidos pela bolsista e pela pesquisadora no sentido que os trabalhadores de enfermagem pareciam ficar mais a vontade com a bolsista e tinham mais liberdade para se ausentar do setor, o que já não ocorria na presença do enfermeiro.

Pensa-se que o levantamento deste percentual contribua nas argumentações de solicitação de pessoal de enfermagem para o CME, pois pelo prisma da gerência de recursos humanos, a enfermagem é uma das profissões mais sujeita a medidas de contenção de custos $^{(18)}$.

No percentual acima foram incluídas as chegadas tardias e saídas antecipadas. Pensa-se que a ausência de uma passagem de plantão formal, a exemplo das unidades de internação, interfira no cumprimento do horário de entrada e saída do funcionário no seu turno de trabalho, pois não há um compromisso cerimonial de reunir todos os trabalhadores no mesmo horário e ambiente para transmitir as informações necessárias à continuidade da assistência. O trabalhador de enfermagem transmite as informações à pessoa que assumirá a mesma atividade que ele estava realizando e este fato não interfere significativamente no tempo efetivo de trabalho.

Há que se considerar que no $\mathrm{CME}$, o processo de trabalho envolve apenas a atividade em si, de transformação de um objeto - material não esterilizado, em um produto - material esterilizado, utilizando os diversos instrumentos de trabalho(8). Nas unidades de internação, há uma troca entre sujeito trabalhador e sujeito que está sendo cuidado, os quais possuem necessidades, vontades e emoções, as quais podem interferir no processo de trabalho da equipe de enfermagem e na própria organização do trabalho( ${ }^{(1,10)}$. Isto não significa que no $\mathrm{CME}$, os trabalhadores também não manifestem suas necessidades, desejos, emoções, porém a relação se dá apenas entre os profissionais.

Há que se salientar ainda, que o próprio ambiente de trabalho, caracterizado como um setor fechado pode 
aumentar o entrosamento ou mesmo as tensões e conflitos. Além disto, pela característica do setor, onde as áreas técnicas realizam processos de trabalhos diferentes, mas são interdependentes, há necessidade de colaboração. Torna-se importante o entrosamento na realização das atividades a fim de processar uma grande demanda de materiais em curto espaço de tempo ${ }^{(14)}$. Estas características podem ter influenciado neste tempo efetivo de trabalho, considerado excelente.

Por fim, é sempre importante considerar que as atividades desenvolvidas no CME são fundamentais para o êxito dos procedimentos cirúrgicos e da assistência terapêutica, principalmente no que se refere a risco de infecção e segurança do cliente ${ }^{(19)}$.

\section{CONCLUSÕES}

Vários são os aspectos que influenciam no tempo efetivo de trabalho pelo pessoal de enfermagem do CME, os quais necessitam de avaliação em cada instituição de saúde e merecem também outros estudos que permitam o aprofundamento dos dados.

Este trabalho mensurou o tempo efetivo de trabalho pelo pessoal de enfermagem do $\mathrm{CME}$, constatando que $\mathrm{O}$ percentual médio foi de $81,20 \%$, sendo considerado excelente de acordo com a classificação adotada por Gaidzinski. O tempo efetivo de trabalho não apresentou alterações significativas relacionadas às áreas de trabalho do CME, aos turnos de trabalho, a demanda de cirurgias do CC, a ausência de pacientes e outros profissionais de saúde no setor, sendo este um dos questionamentos das autoras deste estudo: se as especificidades dos processos de trabalho $e$ principalmente a ausência do paciente seria fator preponderante nesta variável do dimensionamento de pessoal.

Dentro do horário de cada trabalhador o tempo não trabalhado envolveu alimentação, necessidades fisiológicas e resolução de problemas de ordem pessoal. Porém observou-se também que a presença do enfermeiro impunha certo respeito e o pessoal de enfermagem sentia-se mais a vontade para realizar outras atividades quando este não estava presente. Fato constatado pela diferença nos dados coletados pela bolsista.

Estudos sobre dimensionamento de pessoal, principalmente em áreas específicas como a CME são necessários, haja vista a lacuna na produção do conhecimento sobre esta temática. Desta forma, este estudo possibilitou, também, um olhar mais acurado sobre a variável - tempo efetivo de trabalho, o que poderá gerar novos estudos, mas principalmente contribuir de forma significativa com os gestores, que enfrentam no seu cotidiano, a difícil tarefa de dimensionar adequadamente o pessoal de enfermagem, utilizando-se de referencial fundamentado para tal.

http://seer.ufrgs.br/RevistaGauchadeEnfermagem/article/view/4 604/2524.

7. Taube SAM; Méier MJ. O processo de trabalho da enfermeira na central de material e esterilização. Acta paul. enferm. [Internet]. 2007 [cited 2011 set 30];20(4):470-5. Available from: http://www.scielo.br/pdf/ape/v20n4/13.pdf.

8. Taube SAM, Labronici LM, Maftum MA, Méier MJ. Processo de trabalho do enfermeiro na central de material e esterilização: percepção de estudantes de graduação em enfermagem. Ciênc. cuid. Saúde [Internet]. 2008 [cited 2011 set 30];7(4):558-64. Available from: http://periodicos.uem.br/ojs/index.php/CiencCuidSaude/article/vi ew/6674/3924.

9. Conselho Federal de Enfermagem. Resolução COFEN no 293/2004. Fixa e estabelece parâmetros para dimensionamento do quadro de profissionais de enfermagem nas instituições de saúde [Internet] Brasília (Brasil): Conselho Federal de Enfermagem; 2004 [cited 2011 set 30]. Available from: http://site.portalcofen.gov.br/node/4329.

10. Gaidzinski RR, Fugulin FMT, Castilho V. Dimensionamento de pessoal de enfermagem em instituições de ensino. In: Kurcgant P, coordenador. Gerenciamento em enfermagem. Rio de Janeiro: Guanabara-Koogan; 2005.p. 125-37.

11. Fugulin FMT, Gaidzinski RR. Dimensionamento da equipe de enfermagem em unidade de internação. In: Harada MJCS, organizadora. Gestão em enfermagem. Ferramenta para a prática segura. São Caetano do Sul: Yendis Editora, 2011. p. 214-22.

Material e Esterilização e a percepção do seu papel social. Rev Gaucha Enferm [Internet]. 2006 [cited 2011 set 30];27(2):25865. Available from: 
12. Possari, JF; Gaidzinski, RR. Dimensionamento de pessoal de enfermagem em Centro Cirúrgico no período transoperatório: estudo das horas de assistência, segundo o porte cirúrgico. Rev SOBECC. 2003;8(1):16-25.

13. Chagurutu $S$, Vallabhameni BA. Aiding and abetting-nursing crises at home and abroad. N Engl J Med. 2005;353(17):176163.

14. Machado RR, Gelbcke FL. Que brumas impedem a visibilização do centro de material e esterilização? Texto Contexto Enferm. [Internet]. 2009 [cited 2011 set 30];18(2):347-54. Available from: http://www.scielo.br/pdf/tce/v18n2/19.pdf.

15. Malvárez SM, Castrillón-Aguedo MC. Panorama de la fuerza de trabajo en enfermería en América Latina. Rev Enferm IMSS [Internet]. 2006 [cited 2011 set 30];14(3):145-65. Available from: http://www.medigraphic.com/pdfs/enfermeriaimss/eim2006/eim063f.pdf.

16. Pezzi MCS, Leite JL. Investigação em Central de Material e Esterelização utilizando a Teoria Fundamentada em Dados. Rev Bras Enferm [Internet]. 2010 [cited 2011 set 30];63(3):391-6. Available from: http://www.scielo.br/pdf/reben/v63n3/a07v63n3.pdf.

17. Medeiros SM, Ribeiro LM, Fernandes SMBA, Veras VSD. Condições de trabalho e enfermagem: a transversalidade do sofrimento no cotidiano. Rev. Eletr. Enf. [Internet]. 2006 [cited 2011 set 30];8(2):233-40. Available from: http://www.fen.ufg.br/revista/revista8_2/v8n2a08.htm.

18. Ferreira CMBEO, Ferreira SR. Absenteísmo entre os trabalhadores de uma equipe de enfermagem - estudo de caso. Coletânea. 2008;2(2):10-21.

19. Jericó MC, Castilho V. Gerenciamento de custos: aplicação do método de Custeio baseado em Atividades em Centro de Material Esterilizado. Rev Esc Enferm USP [Internet]. 2010 [cited 2011 set 30];44(3):745-52. Available from: http://www.scielo.br/pdf/reeusp/v44n3/28.pdf.

Artigo recebido em 27.05.2010.

Aprovado para publicação em 09.09.2011.

Artigo publicado em 30.09.2011. 